\title{
PROYECCIÓN HISTÓRICA DE FRANCISCO SUÁREZ: XAVIER ZUBIRI
}

\author{
JAVIER MONSERRAT \\ Universidad Autónoma de Madrid
}

\begin{abstract}
RESUMEN. La obra epistemológica y metafísica de Francisco Suárez supuso un cambio importante en la filosofía escolástica. Por ello ha sido denominada como la Segunda Escolástica. En realidad, más que un "cambio» o "reforma" del tomismo, es una verdadera alternativa. En Suárez tienen su eco el pensamiento nominalista y la ciencia moderna. Estos puntos de referencia nos hacen entender por qué Suárez dijo lo que dijo. En alguna manera intuyó lo que su tiempo significaba. El tomismo puro asumió una interpretación «dura» del dualismo griego y esto había dado lugar a la teoría de la prevalencia del universal en el proceso cognitivo. El nominalismo y la ciencia moderna no iban en esta línea. Para ellos, la mente humana se construía a partir de la experiencia, en la línea del sensismo y del empirismo posterior. Suárez, en efecto, cambió también de perspectiva, haciéndola más conforme con su tiempo, al reconstruir el proceso del conocimiento a partir de la teoría epistemológica de la prevalencia del singular sobre el universal en el proceso cognitivo. Durante los siglos siguientes, la obra de Suárez supuso una alternativa eficaz frente al tomismo puro, sobre todo por la obra docente de los jesuitas. Por ello, el estilo filosófico de Suárez se extendió por toda Europa y marcó una línea de presencia filosófica en España. Creemos que puede hablarse de una constante filosófica española que recoge las grandes líneas de Suárez. Esta manera de pensar se ha proyectado, o ha fructificado, en el siglo XX, en autores como Amor Ruibal y Zubiri. En este artículo mostraremos la conexión entre la epistemología de Suárez y la de Zubiri.
\end{abstract}

PALABRAS CLAVE: Suárez; Zubiri; teoría del conocimiento; singular; universal; proceso cognitivo.

\section{Historical projection of Francisco Suárez: Xavier Zubiri}

ABSTRACT. The epistemological and metaphysical work of Francisco Suárez represented an important change in scholastic philosophy. Therefore it has been denominated like Second Scholastic. In fact, more than a "change» or «reform» of Thomism, it is a real alternative. In Suarez have their echo both nominalism and modern science. These points of reference make us understand why Suarez said what he said. Pure Thomism assumed a «hard» interpretation of Greek dualism and this had given rise to the theory of the prevalence of the universal in the cognitive process. Nominalism and modern science did not go along this line. Suarez also changed perspective, making it more conformable with his time, by reconstructing the process of knowledge from the epistemological theory of the prevalence of the singular over the universal in the cognitive process. During the following centuries, the work of Suarez was an effective alternative to the pure Thomism, mainly by the educational work of the Jesuits. For this reason, the philosophical style of Suárez marked a line of philosophical presence in Spain. We believe that it is possible to speak of a constant Spanish philosophical style that picks up the great lines of Suárez. This way of thinking has been projected, or has fructified, in the twentieth century, in authors like Amor Ruibal and Zubiri. In this article we will show the connection between the epistemology of Suárez and that of Zubiri.

KEY WORDS: Suárez; Zubiri; theory of knowledge; singular; universal; cognitive process.

Quiero establecer desde el comienzo de este artículo que nuestra referencia a Suárez está limitada a su filosofía fundamental, a su «filosofía primera», a su teoría del conocimiento (epistemología), y al origen lógico de su crítica del sistema tomista, así como a la estructura lógica de su metafísica. Por tanto, no 
vamos a mencionar otras profundas dimensiones de su filosofía, como son la teología (vg. su teoría de la gracia y de la libertad), la filosofía del derecho y la filosofía política (vg. la ley natural, el origen de la autoridad, de la soberanía popular). Aunque la dimensión teológica, la jurídica y su filosofía política, por su evidente importancia temática, son más conocidas, no son las más importantes, a mi modo de entender. Es más importante el fundamento lógico de su sistema.

En primer lugar, nos referimos a las líneas clásicas del pensamiento tomista, con el objetivo de tener un punto de referencia definido que nos permita entender la aportación de Suárez. En segundo lugar, presentaremos la alternativa de Suárez. En tercer lugar, mostraremos cómo muchas de sus ideas epistemológicas, así como metafísicas, se han proyectado sobre la visión moderna de Xavier Zubiri.

\section{La estructura lógica del Pensamiento tomista}

La filosofía clásica griega, ante todo platónico-aristotélica, había partido de tres experiencias esenciales: la experiencia del ser, la experiencia de la movilidad y la experiencia del carácter absoluto del conocimiento humano, especialmente en el orden del conocimiento moral. De ahí nacen la intención cosmológica de los primitivos presocráticos; la problemática ontológicocosmológica de Parménides y Heráclito; la crisis de la coherencia racional de los presocráticos; la consecuente crisis teorética y moral de la antropología sofista; la reivindicación existencial de la absolutez moral del hombre en Sócrates, y todo ello hasta llegar a la solución platónica al problema del saber y de la antropología, ya a un solo paso del nacimiento del sistema de Aristóteles.

De esta confluencia de problemas nace la filosofía tomista, en clara vinculación medieval a Aristóteles. Para el tomismo, la realidad móvil (la realidad de experiencia que presenta de hecho, en la unidad objetiva de la cosa real, el ser y el movimiento) solo puede ser pensada, si se percibe en ella una cierta unidad compatible con la movilidad. Las cosas reales deben pensarse realizando un acto de ser que funde la unidad y la predicación estable del conocimiento y del lenguaje. En definitiva, la realidad móvil solo podrá ser conocida si se advierte en ella la presencia real de un Principio (o causa) constitutivo de Movilidad y, al mismo tiempo, un Principio (o causa) constitutivo de Unidad. La realidad, conocida sensiblemente como movimiento y como ser, solo podrá explicarse si se afirma una causa del movimiento (principio de movimiento) y una causa del ser (principio de ser, o de unidad).

Esto permite deducir rigurosamente la estructura lógica de la epistemología y la metafísica fundamental (filosofía primera) del tomismo. Hablamos aquí del tomismo desde su interpretación más importante históricamente: el tomismo 
puro $^{1}$. Esta interpretación del tomismo tiene su origen en el dominico Cardenal Tomás de Vio, Cayetano. Ante el acoso de las doctrinas nominalistas y la crisis de la época, Cayetano hizo una reformulación lógica de las tesis básicas del tomismo, con la idea de contribuir a su reforzamiento frente a los ataques ${ }^{2}$.

\subsection{El Principio de Unidad: el acto}

El principio de unidad debe estar causado por el acto, o sea, perfección, ser, operatividad, coherencia, unidad consigo mismo. Pero, por la influencia de la metafísica de Parménides, la perfección del acto de ser es, de por sí, estática, no puede ir más allá de la permanencia en sí mismo (el ser es lo que es y permanece en sí mismo). El Principio, o causa, del Ser no puede, por la lógica del mundo griego, ser principio de movilidad ${ }^{3}$.

\subsection{El Principio de Movilidad: la no-actualidad en absoluto}

Para el tomismo, el principio de movimiento no debe tener acto (ser) en absoluto y, por su no-actualidad, debe entorpecer, limitar, la perfección, o sea, del principio de unidad (ser). Si el principio de movilidad tuviera, él mismo, unidad, ser, acto, nunca podría ser pensado como causa de la movilidad; no explicaría la presencia del movimiento, puesto que él mismo debería causar el

1 La interpretación del tomismo, tomismo puro, que aquí presentamos responde a la renovación del siglo XVI por obra de Tomás de Vio, Cayetano. A comienzos del siglo XX hubo un movimiento para que la iglesia católica reconociera como doctrina oficial al tomismo. En este movimiento destacan dos obras (citamos las ediciones manejadas): Matriussi, S. I., Guido, Le XXIV tesi della filosofía di Tommaso d'Aquino, Universitá Gregoriana, Roma, 1947 (la segunda edición es de 1925); MAnser, G. M., Das Wesen des Thomismus, Paulus Verlag, Freiburg in der Schweiz, 1949 (tercera edición), traducida al español, La esencia del tomismo, CSIC, Madrid, 1947. Como referencia básica al tomismo consideramos también estas referencias: Giacon, C., Le grandi tesi del tomismo, Pàtron, Bologna, 1947; GiLson, E., El tomismo. Introducción a la filosofía de Santo Tomás de Aquino, EUNSA, Pamplona, 1978 (1922); Setilanges, A. D., S. Thomas D’Aquin, Felix Alcan, Paris, 1912 (tomo I); GarrigouLagrange, R., La Synthèse Thomiste, Paris, 1951 (segunda edición). También: Fabro, C., Breve Introduziones al Tomismo, Obras Completas, vol. XVI, Roma, 2007 (1960); Tomismo e pensiero moderno, Librería Editrice Lateramense, Roma, 1969; Esegesi tomística, Librería Ed. Lateranense, Roma, 1969; La nozione metafísica di partizipazione, secondo S. Tomaso d'Aquino, Obras Completas, vol. 3, Roma, 2005.

2 Los orígenes de la escuela del tomismo puro, que dio la pauta interpretativa desde el siglo XVI, se atribuye a la obra del dominico Cardenal Tomás de Vío, Cayetano. Está en línea con el tomismo posterior de Mattiussi y Manser. Nos remitimos a: Alfaro, S. I., Juan, Lo natural y lo sobrenatural según el Card. De Vio, Cayetano. Contenido, Fuentes, Originalidad, Universitá Gregoriana, Romae, 1950; Thомаe de Vio, Caietani, De ente et essentia. D. Thomae Aquinatis Commentaria, Marietti, Taurini, 1934; Tномаs de Vio, Cardinalis Caietano, Scripta Philosophica. Commentaria in De Anima Aristotelis, vols. I-II, Angelicum, Roma, 1938; Scripta Philosophica. De nominu analogia. De conceptu entis, Angelicum, Romae, 1934.

3 Mattiussi, o.c., caps. I, II, III; MANSER, o.c., p. 255-795. 
ser estable, en tanto en cuanto tuviera ser. Por ello, para el tomismo quedó claro que el principio de movilidad, por él mismo, no podía tener ser-en-absoluto, debía ser una no-actualidad en absoluto ${ }^{4}$.

\subsection{Limitación real del acto por la materia, o principio de movimiento}

Por tanto, el principio de movilidad, por no ser acto (ser), sino pura multiplicidad, sin unidad, debía entorpecer la realización del ser (del principio de unidad) con un entorpecimiento físico, enteramente real. Ambos principios, para el tomismo, debían ser entendidos como reales, presentes en las cosas mismas; si no fuera así no podrían producir el ser y el movimiento que se manifiestan en la experiencia. Esta co-existencia, en las cosas mismas, de ambos principios, explica que el ser quede entorpecido y no pueda manifestar su plena perfección ${ }^{5}$.

\subsection{La co-principialidad de la materia y la forma: la distinción real}

Por tanto, si llamamos «materia» al principio de movilidad y «forma» al principio de unidad o ser, se afirma, en el tomismo, que las cosas están constituidas por dos co-principios internos que la determinan en las propiedades de experiencia. La materia y la forma deberán ser pensadas como una distinción real o física, existente en las cosas mismas. La distintio realis es así uno de los principios básicos del tomismo. Esta distinción, física y real, es la que explica la existencia de una real limitación del acto, o ser, por la materia. Forma y Materia debían estar «dentro» de las cosas mismas, puesto que en ellas debían ser la causa real del ser y del movimiento. La distintio realis suponía, pues, al mismo tiempo, la afirmación de la unidad de las cosas reales en una única substancia: era la llamada unión substancial entre materia y forma ${ }^{6}$.

\subsection{La teoría acto-potencia: el movimiento}

El ser, por tanto, no solo existe en acto, sino también en potencia, en relación a su posible plenitud, no conseguida por el entorpecimiento de la materia. Desde esta teoría potencia-acto (consecuencia de la teoría de la distinción real) nace la clásica explicación aristotélica del movimiento, asumida por el tomismo. El movimiento es el acto mediante el cual la forma va avanzando, progresivamente, hacia la perfección que correspondería al ser propio de cada una de las formas. Las formas van oscilando (moviéndose) en la realización de su potencia, que nunca queda cumplida por la obstrucción real de la materia ${ }^{7}$.

\footnotetext{
MANSER, o.c., p. 717-737.

Mattiussi, o.c., p. 14-25; Manser. o.c., p. 717-737.

Mattiussi, o.c., cap. V; Manser, o.c., p. 536-609.

MANSER, o.c., p. 105-120.
} 


\subsection{La ilimitación del acto y el principio de individuación}

Por sí misma, la materia es pura no-actualidad, pura multiplicidad, sin acto o ser alguno. Aristóteles dijo, en el libro de la Física, que la materia era «pura potencialidad para ser» (diríamos que la materia era pura capacidad de ser integrada en la unidad del ser de las cosas reales, por obra de las formas, o principios de ser). En cambio, el acto, por sí mismo, es la perfección absoluta, plena, del ser que le corresponde (cada forma tiene un ser específico propio de ella, así ser del árbol, del animal, del hombre, cada uno con distinta perfección de ser). Es decir, el acto, la forma, es ilimitada dentro de la línea específica en que es «ser» (si no estuviera limitado por la materia la forma sería perfecta, ilimitada en su grado de perfección). Esta es la teoría tomista del actus illimitatum ${ }^{8}$.

\subsection{El proceso cognitivo como abstracción des-materializante}

Ahora bien, esto supuesto, para el tomismo, ¿cómo se deberá concebir entonces el proceso de conocimiento por el que la mente entiende efectivamente la realidad, es decir, se apropia de la verdad? La materia es, de por sí, la pura multiplicidad, sin coherencia ni unidad alguna, el no-ser, la no-actualidad en absoluto, y, por tanto, la materia es completamente incognoscible. Para que fuera cognoscible debería tener cierta permanencia estable en sí misma que fundara la afirmación (decir «esto es tal cosa» con la pretensión inherente de que este conocimiento se mantuviera). La materia, al contrario, por su mismo concepto, era puro devenir, sin permanencia alguna: no podría decirse de la materia "es esto" porque ya habría dejado de serlo. De ahí el principio tomista de que la materia no podía ser objeto de conocimiento: su incognoscibilidad absoluta. Por consiguiente, la experiencia sensible de la realidad muestra a los seres reales en su unidad. Pero en lo sensible hay una presencia de la materia y de la forma. Lo que sensiblemente se presenta como huella de la materia no puede ser conocido. Por ello, en el conocimiento, la mente humana debe «abstraer» lo que en la realidad sensible hay de cognoscible (sólo las formas) y separarlo de lo material. Lo que se conoce son las formas y, para ello, es necesario, según el tomismo clásico, un proceso previo de abstracción que parte de las sensaciones.

\subsection{El universal tomista: su prevalencia en el proceso cognitivo}

De esto se deduce una de las afirmaciones más importantes del sistema tomista: la mente es la facultad del universal, es decir, de la forma, del acto que es de por sí ilimitado. El acto, la forma, al ser abstraído por la mente, se ilimita en la abstracción, se hace perfecto en su línea de perfección (árbol, animal, hombre), ya que se separa de la materia que constriñe el acto. ¿Cómo se conoce

8 MANSER, o.c., p. 767-794. 
entonces el singular, cuya presencia se advierte objetivamente en la experiencia sensible? El singular, para el tomismo puro, se conoce por una reducción aproximativa al resultado de la limitación de la universalidad de la forma por la materia signata cuantitate (esta era la sentencia medieval). Para el tomismo puro el singular es, en el fondo, incognoscible, porque en él tiene una presencia causal el no-ser de la materia. La materia es, pues, un mero concepto límite negativo que se afirma como condición de posibilidad del conocimiento de una realidad objetiva, cuyo ser presenta una extraña movilidad (extraña porque el ser era, para los griegos, estable en sí mismo, permanente, desde la tradición instaurada por Parménides). Pero por sí misma, la materia es incognoscible. Para el tomismo, por tanto, según una tradición mantenida, que se remonta a la lógica del pensamiento griego, lo primero que se conoce es el universal. Este, al abstraerse, se hace ilimitado (sin la restricción limitativa de la materia); pero ilimitado, o perfecto en su línea (es la perfección del acto, o forma, en la perfección del vegetal, del animal, del hombre). El singular se conoce al verlo objetivamente desde el horizonte del universal: es cuando se dice, «esto es un árbol» (una singularización concreta del universal «árbol» producida por una individuación, resultado de la unión del universal, o forma, a la materia) ${ }^{9}$.

\subsection{El «ser universal»: el ente como primer transcendental de la mente}

El tomismo recogió también la doctrina lógica aristotélica que distinguía entre conceptos categoriales (que pueden darse o no darse) y el concepto transcendental o concepto de «ser» (transcendental porque transciende todo posible conocimiento al no poder dejar de concebirse, ya que todo lo que pueda conocerse es «ser», siempre, de manera necesaria). Todo tiene «ser»y, por tanto, el ser es universal. Es decir, cuando se abstrae una forma y se universaliza, como hemos explicado, en esa forma está contenido el ser (de esa forma). Como tal, al menos así pudiera parecer, el ser se haría universal. Pero, ¿tiene esto sentido? El tomismo advirtió que no lo tenía. El ser no podía predicarse unívocamente de todos los seres en el mismo sentido: desde Dios a las formas más simples. Pensaron que, en esta línea, podía caerse en una especie de panteísmo. La solución estaba ya dada en la misma lógica del tomismo. En efecto, la forma, al abstraerse, incluía el transcendental «ser», pero era sólo el «ser» propio de esa forma. No estaba presente un «ser universal», sino sólo el ser propio de esa forma, específico, limitado sólo a la perfección de esa forma. Por esto, la estabilización de la mente humana en la abstracción del primer transcendental no se consigue sino a través de tres momentos complementarios, que podrían describirse como sigue: 1) abstracción del principio causante de la unidad, el ser, de tal manera que se produce en la mente la ilimitación del acto de ser, esto es, sobre lo que los tomistas llaman el Esse; 2) captación, dada en lo sensible por el movimiento, complementaria de la negatividad del principio de multiplicidad,

9 MANSER, O.c. 257-253. 
de la materia, o sea, la captación de la «esencia» limitante (esencia es «lo que es» una cosa real, un árbol, un animal, el hombre, tienen sus esencias diferenciadas); 3) afirmación sintética del «ente», o realidad co-principiada por esencia y existencia, con distinción real entre ellas; lo que se conoce, por tanto, es un «ente», es decir, un ser de la naturaleza que corresponde a su esencia (ser del árbol, del animal o del hombre). Por consiguiente, en el tomismo, el primer transcendental de la mente (el ser) no es el Esse simpliciter, sino el Esse en cuanto co-afirmado en el «ente», es decir, el «ente» en cuanto abarca la esencia y la existencia (se abstrae el «ser» de una determinada «esencia», no se abstrae el Esse simpliciter o un mero "ser universal» en el sentido tomista, que se predicara unívocamente de todas las cosas) ${ }^{10}$.

\subsection{Conclusión}

El pensamiento tomista presentó un conjunto de afirmaciones extrañas, difíciles de entender, pero que, en cierta manera eran una consecuencia estrictamente lógica de sus postulados básicos, extraídos de la ontologíaepistemología griega. En resumidas cuentas lo que viene a decir el tomismo es que cuando la mente humana, el hombre como ser racional, que quiere conocer la realidad sensible objetiva, se enfrenta a las cosas reales (en que coinciden sensiblemente el ser y el devenir, la unidad y la multiplicidad de estados), no puede hacerlo sin separar de inmediato lo cognoscible de lo incognoscible, la forma de la materia, de tal manera que se abstrae entonces el universal y el singular se conoce como realización concreta de esa forma universal por obra de un principio limitante o materia, que de por sí es incognoscible. Además, esto suponía, como hemos dicho, que los universales, en potencia, estaban presentes en las cosas mismas (no eran un mero concepto), tal como se había defendido en la teoría de la distinción real entre esencia y existencia ${ }^{11}$. La afirmación de la existencia de los universales in re tuvo muchas resistencias a lo largo de los siglos XV y XVI, hasta el punto de que el tomismo se vio obligado a reformular la estricta lógica de su pensamiento para defenderla de sus contradictores; esta fue la obra del cardenal Tomas de Vio, Cayetano, que inicia la escuela del llamado «tomismo puro», tal como antes explicábamos.

Este criticismo persistente, desde el siglo XV, y antes, acabó tomando forma en la corriente sistemática del pensamiento nominalista, con Guillermo de Ockam como principal representante. Para el nominalismo los universales no son sino «nombres» (que tienen de fondo un «concepto» nacido de la experiencia sensible) que el hombre pone a las cosas sensibles. Los nombres son flatus vocis que no hacen sino apuntar deícticamente al mundo sensible.

10 MANSER, O.c., p. 284-310.

11 El novelista Umberto Eco, en El nombre de la rosa, alude a las discusiones que la teoría de los «universales en las cosas misma» suscitaba en su tiempo, como se ve en las discusiones de los monjes que replantean apasionadamente las consecuencias «duras» del tomismo, probablemente ya ante las críticas nacientes del nominalismo. 
Es, pues, explicable que el nominalismo llevara en germen no solo una filosofía del lenguaje, sino también una teoría del conocimiento, congruente con lo que iba a ser la epistemología de la naciente ciencia moderna ${ }^{12}$.

Para el nominalismo y para la ciencia moderna, la reconstrucción del proceso de instalación de la mente humana, la razón del hombre, no estaba ya lastrada por la idea parmenidea del Ser, que producía la contradicción sensible entre el ser y el devenir, induciendo a radice un conocimiento de lo real fundado en la abstracción de los universales. Al contrario, nominalismo y ciencia comenzarán a entender que la mente se construye sobre la constatación de los hechos sensibles, objetivos, que se imponen por sí mismos: es un hecho que las cosas tienen una estabilidad, un ser, una permanencia, pero, al mismo tiempo, tienen también un movimiento, una evolución, una inestabilidad o devenir. ¿Por qué las cosas reales que se imponen a la mente humana por experiencia sensible inmediata son efectivamente así? Este es un problema real que la mente humana irá advirtiendo poco a poco y que deberá resolverse más adelante. Es un problema que todavía hoy sigue abierto. Pero, de inmediato, la mente humana describe el mundo de experiencia, tal como está inmediatamente constituido. Lo va conociendo poco a poco y esto la irá poniendo en condiciones de preguntarse últimamente cuáles son las causas de que el mundo sensible sea como es. El tomismo, pues, plantea y resuelve $a$ radice el problema del ser y el devenir mediante una teoría dualista que exige la abstracción de los universales in re. El mundo moderno no elude el problema del ser/devenir pero afirma la inteligibilidad objetiva del mundo sensible y muestra que la mente humana comienza a construirse por el conocimiento de ese mundo de experiencia sensible, que debe describirse para fundar entonces las inferencias que pudieran hacerse para su conocimiento.

\section{Francisco SuÁrez y la SEgunda escolástica}

A medida que, durante el presente siglo, fue extendiéndose la corriente neotomista transcendental, kantiano-existencialista, pareció una actitud casi obligada la crítica contra el esencialismo suareciano. En realidad, el pensamiento

12 Roig Gironella, J., «Para la historia del nominalismo y de la reacción antinominalista de Suárez», en: Pensamiento, n. 67 (1961) 279-310; Defez i MARtin, A., «Realismo esencialista y nominalismo irrealista: acerca de la objetividad del conocimiento del mundo», en: Pensamiento, 54 (1998) 417-442; Landesman, C. (Ed.), The problem of Universals, Basic Books, New York, 1971; ANDRÉs, T. de, "Actividad del entendimiento y formación del universal en la psicología de Guillermo de Ockham», en: Miscelánea Comillas, n. 47-48 (1967) 267-287; Significación representativa y significación lingüística en la lógica de Guillermo de Ockham, Bedia, Madrid, 1966; «La significación representativa de Guillermo de Ockham», en: Pensamiento, n. 96 (1968) 375-381; podemos también referirnos a la obra de José María de Alejandro (antiguo profesor de teoría del conocimiento en la U.P. Comillas), titulada $\mathrm{La}$ gnoseología del Doctor Eximio y la acusación nominalista, Publ. Anejas a Miscelánea Comillas, vol. 1, Comillas 1948, así como a su artículo «Gnoseología de lo singular según Suárez», en: Pensamiento, n. 12 (1947) 403-425. 
de Gilson, a mi manera de entender, es fruto de una confusa comprensión de la problemática existencialista y de una no menos deficiente idea del sentido profundo de la filosofía de Suárez. El escolástico suarista J. Hellín ${ }^{13}$ mostró en un artículo muy completo que, en contra de la tesis de Gilson, no tiene sentido decir que Suárez sea un filósofo esencialista. En el fondo, todo el error de la especulación de Gilson consiste en considerar la esencia como algo abstracto y no, más bien, el fundamento mismo de la realidad. Si la esencia es el «lo que» es una cosa real, nos estamos refiriendo al modo de ser real de la cosa. Este factor real, no abstracto, es lo que posee, como diría Zubiri, un carácter principial de realidad.

Para entender lo que Suárez pretende decir, debemos atender a la autoexperiencia propia. Observamos que la experiencia radical, inmediata de nuestro propio ser, nuestra subjetividad, nuestro «acto» vital, se presenta intramundanamente dado en unas ciertas formas reales objetivas que presentan una unidad convergente: la corporalidad, la extensión espaciotemporal, la unidad de acción y de todas nuestras propiedades, nuestro autodominio, etc. Este sistema real de notas reales, físicas, dadas en nuestra experiencia, es lo que nos hace aprehender nuestro propio «ser». Pues bien, lo que dice Suárez es, en definitiva, que la aprehensión del ser, del acto, está siempre dada necesariamente a través de una «esencia objetiva». En un primer momento, el discurso de la mente, de la razón humana, discurre ponderando las características de esa «esencia objetiva» que es de por sí inteligible. Esa esencia tiene, en efecto, ser, pero la discusión del problema ser/devenir no se hace en un primer momento, como dice el tomismo (pasando a establecer de inmediato, en el inicio mismo del conocimiento, el dualismo materia/forma), sino que se aparca a un momento posterior. Será precisamente el conocimiento desarrollado acerca del ser de la «esencia objetiva» lo que permita más adelante hallar una solución al problema del ser/devenir ${ }^{14}$.

13 Hellín, J., S. J., «Sobre el ser esencial y existencial en el ser creado (desde el punto de vista suareciano)», en: Congreso Internacional de Filosofía, Barcelona, 1948, Madrid, 1949, 519-561; «Líneas fundamentales del sistema metafísico de Suárez», en: Pensamiento, vol. 4 (1948) 123-168; «Sobre la limitación del acto por la potencia», en: Las Ciencias, año XVI, n. 2, Madrid, 329-365; «Sobre la raíz de la limitación del ser según el P. Suárez», en: XIII Congreso luso-espanhol para o Progresso de las Ciéncias, $6^{\mathrm{a}}$ Seccao, Ciencias Filosóficas y Teológicas, Lisboa, 1950, 69-110; «Esencia de la relación predicamental según Suárez», en: Las Ciencias (1958) 648-696; La analogía del ser y el conocimiento de Dios en Suárez, Madrid, 1947.

14 NeIDL, W. M., Der Realitäts Begriff des Franz Suareznach den Disputationes Metaphysicae, M. Hueber Verlag, München, 1966; DARGE, R., Suárez' transcendentale Seinsauslegung und die Metaphysiktradition, Brill, Leiden/Boston 2004; LaRranizar, C., Una introducción a Francisco Suárez, EUNSA, Pamplona, 1977; Fernández, C., Metafísica del conocimiento en Suárez, Estudios Onienses, Madrid, 1954; Facultad de Filosofía de la Compañía de Jesús, Chamartín de la Rosa, Madrid, Francisco Suárez, S.I., El hombre y el filósofo (1548-1948), Madrid, 1948; Pensamiento, vol. 4. Número extraordinario, 1948. Dedicado a Francisco Suárez en el cuarto centenario de su nacimiento (1548-1948); Fuetscher, L., S. J., Akt und Potenz. Eine kritischsystematische Auseinandersetzung mit dem neuren Thomismus, Felizian Rauch, Insbruck, 1933; Acto y Potencia. Debate crítico-sistemático con el neotomismo, Razón y Fe, Madrid, 1948. 


\subsection{La intuición radical de Suárez}

En efecto, su intuición radical (aquella de la que se deriva lógicamente todo el sistema) consiste en haberse dado cuenta de que la aprehensión de un ser (actus), dado en la sensibilidad material en que nos movemos inmediatamente, lleva consigo una previa aprehensión del carácter coherencial de la manifestación objetiva de lo real. La intuición de que el ser objetivo se entiende inicialmente como la aprehensión de un sistema de notas coherentes, relacionadas unas con otras en armonía, fundando así la unidad del ser objetivo. Ese sistema armónico de notas físicas reales es lo que funda la aprensión del ser. Pero ese sistema de notas, o «esencia objetiva», es comprensible por sí mismo. Esta esencia objetiva muestra todas aquellas notas que significan una «aptitud para ser» (aptitudo ad essendum). La razón humana discurre inicialmente orientada al conocimiento de esa «esencia objetiva». Podríamos desgranar esta intuición básica de la siguiente manera.

Objetividad sensible de la esencia. El ser se aprehende siempre en un contexto intramundano, pero desde el transfondo comprensivo que posibilitan las notas de una "esencia objetiva» con "aptitud para ser». Se aprehende el ser porque hay una esencia objetiva que, por su coherencia y unidad inmediata, manifiesta la presencia de ese «ser». Usando terminología de Zubiri, podríamos decir que la aprehensión de la esencia es el conocimiento objetivo de un sistema cíclico y clausurado de notas físicas, reales, o «sistema sustantivo» (sustantivo porque es fenoménico, algo físico o real que induce un "nombre», un sustantivo «nombrable», como diría el nominalismo). De este sistema puede predicarse el «ser».

Primer discurrir de la razón: el singular afirmable. Por tanto, la afirmación del ser se realiza en una pre-apertura de la razón a su coherencia objetiva, esencia objetiva, como singularidad objetiva cognoscible. Para Suárez no tiene, pues, sentido hablar de la incognoscibilidad de la materia, al estilo del tomismo puro. De ahí que lo que se conoce inicialmente es la formalidad objetiva, el sistema coherencial de notas que constituyen un ser singular concreto. Este singular es cognoscible por sí mismo, directamente, sin recurrir a la prevalencia del universal al estilo tomista.

El sistema de Suárez: ser, devenir, contingencia. En consecuencia, conocer el mundo objetivo no exige la afirmación, digamos dialéctica e inmediata, de la dualidad forma/materia, con la materia como pura negatividad, no-ser en absoluto. El camino de la razón puede discurrir, a partir del conocimiento del singular afirmable, hasta llegar, a través de un itinerario fundado en el singular, que constituye el cuerpo de la metafísica de Suárez, al llamado «juicio de contingencia». Este juicio nos dice que el ente mundano no posee en sí mismo la razón suficiente de su existencia, esto es, no posee suficiencia existencial, y, en consecuencia, se llega a la necesidad de afirmar la existencia fundamental del Ipsum Esse Subsistens, que, como causa primera creadora e inteligente, 
ha creado los diversos modos esenciales del mundo y de los seres que lo constituyen. Es decir, el discurso sobre el ser, que se abre por el conocimiento de las esencias, hace posible que el problema del ser/devenir (que busca dónde situar la absolutez fundamental del ser) no se resuelva colocando el ser pleno en las formas aristotélicas (que, son lo que son y no pueden dejar de ser, según la tradición parmenidea), como hace el tomismo a través del dualismo materiaforma, sino que la absolutez del ser se coloque en el Ipsum Esse Subsistens que funda el ser contingente (unido al movimiento y al devenir) de los seres que constituyen el mundo. La estabilidad del ser que no poseen los singulares objetivos (son contingentes) no debe atribuirse a las formas (aristotélicoparmenideas), sino a la existencia fundamental del Ipsum Esse Subsistens.

Pero veamos con algo más de detalle la estructura lógica del sistema de Suárez ${ }^{15}$.

\subsection{La estructura lógica del sistema metafísico de Suárez}

Para mayor claridad podemos resumirla en bloques lógicos.

Teoría de la prevalencia del singular en el proceso cognitivo. Es el verdadero fundamento y origen lógico de su sistema epistemológico-metafísico. También para el tomismo, como antes hemos expuesto, su teoría de la prevalencia del universal en el proceso cognitivo es fundamental, básica, y radical porque de ella se originan las tesis restantes del tomismo puro. De ahí que la diferencia entre tomismo y Suárez sea epistemológica en sus raíces. Suárez, al negar la prevalencia del universal y la presencia de los universales in re, se une a las críticas, ya antiguas, desde los siglos XIV-XV, de la filosofía nominalista que anticipó la manera de pensar de la ciencia moderna. De hecho, a lo largo de los siglos XVI-XX, la discusión sobre la prevalencia del singular o del universal en el proceso cognitivo fue una de las discusiones habituales entre las escuelas escolásticas suarista (principalmente jesuitas) y tomista (principalmente dominicos).

Los conceptos universales: conocer como proceso inductivo del singular. Pero, si el conocimiento comienza in representando las propiedades esenciales del singular objetivo, ¿cómo entender entonces los conceptos universales? ¿Qué son? Suárez, dada la importancia del universal en la epistemología tomista tradicional, debía ofrecer una explicación del origen y naturaleza de los conceptos universales. Y, en efecto, lo hizo. Para Suárez el proceso cognitivo depende del proceso de inducción que es inherente a la experiencia repetitiva

15 Para una exposición de Suárez atendiendo a la lógica de su sistema me refiero a: IturRia, Gregorio, Compendium Metaphysicae eximii doctoris P. Francisci Suárez, S. J., E. T. Fontanet, Madrid, 1900; Courtine, J.-F., Suarez et le système de la metaphysique, PUF, Paris, 1990; Roig Gironella, J., «La síntesis metafísica de Suárez», en: Roig Gironella, J., Investigaciones metafísicas, Ed. Atlántida, Barcelona, 1948, 125-218; de RoIg GIRonella puede verse también: Curso de cuestiones filosóficas, Juan Flors, Ed., Barcelona, 1963. 
de las cosas. No podemos dejar de recordar la importancia que la inducción de experiencias singulares tuvo tanto para el nominalismo (Guillermo de Ockam) como para la ciencia (Francis Bacon). ¿En qué consiste la inducción? La experiencia repetida de una clase específica de singulares permite conocer su coincidencia en una serie de propiedades que justifican formar, por ejemplo, los conceptos universales de «vegetal» o «animal» (conceptos que abarcan a todos los singulares que poseen esas propiedades específicas de clase). Universales que podrán dar lugar a otras clases derivadas de universales al añadir más diferencias específicas, hasta llegar a los singulares dentro de una clase universal. La lógica aristotélica era perfectamente aplicable a esta idea inductiva de los conceptos universales; en nuestra opinión, la lógica de Aristóteles se armonizaba mejor con Suárez que con el tomismo.

El concepto universal de ser. De la misma manera que, por inducción, se forman los conceptos universales, así igualmente se forma el concepto de ser. La experiencia de cualquier singular por los sentidos coincide en ciertas propiedades, en el grado de máxima generalidad posible. Hasta el punto de que, por extensión, cualquier singular, al que se pudiera tener acceso por la experiencia sensible, debiera tener también esas propiedades. Es más todavía, cualquier cosa que fuera real y existente, aunque estuviera fuera del alcance de la experiencia humana, debería poseer también esas propiedades de clase. Nos estamos refiriendo, como se ve, al concepto universal de ser, al que se tiene también acceso por medio de un proceso inductivo. Todo aquello que pudiera tener realidad y existencia, o que la tenga de hecho, debe realizar el concepto de ser. De ahí, de acuerdo también con la lógica aristotélica, que el concepto de ser sea el primer, y único, transcendental de la mente humana racional. Es un concepto que «transciende» a toda posible realidad, es decir, está incluido en toda posible realidad. Todo lo real y existente deberá asumir las propiedades de clase del concepto «ser».

Teoría inductiva de la ciencia. Como se ve, esta epistemología o teoría del conocimiento de Suárez es perfectamente armonizable con la teoría inductiva de la ciencia que llevará a la escuela empirista de los siglos XVII y XVIII. Para los empiristas, los enunciados universales de la ciencia nacen de la generalización de casos singulares: La propiedad A se cumple en el caso 1, en el 2, en el 3... en el caso $\mathrm{n}, \mathrm{y}$, por inferencia, se generaliza que se cumplirá también en el caso $\mathrm{n}+1^{16}$.

16 Adviértase que la teoría de la ciencia a que llevan los supuestos epistemológicos básicos del sistema de Suárez es la misma que iba a ser formulada por el empirismo en los siglos XVII y XVIII. En ambos casos es una teoría inductiva de la ciencia. Esta posición es el enfoque moderno de la ciencia, que se irá construyendo en los siglos siguientes, hasta la actualidad. Su principio básico es que los seres vivos han surgido en un proceso evolutivo y su «mente», su razón, se ha conformado poco a poco, en un proceso aposteriori, que hace depender de la experiencia los contenidos de la mente. Esto planteó el problema del fundamento para la «universalidad y necesidad» del conocimiento (que el empirismo no podía justificar y en Suárez habría que ver), que los racionalistas resolvieron atribuyendo a la razón contenidos o principios «a priori» (digamos, «de fábrica»), pertenecientes a la pura razón como tal y que 
Analogía del ser. Tal como explica Suárez la formación inductiva del concepto de ser, resulta que un mismo «paquete conceptual» (el concepto de ser) se aplica a todos los seres reales y existentes de experiencia, y a todos los que existieran más allá de la experiencia sensible del hombre. Incluso aquellos seres que la mente humana pudiera «imaginar» deberían responder igualmente a ese mismo paquete conceptual. Es, pues, un "paquete» que se atribuye a todo posible ser existente. Ahora bien, esto planteó un problema en la filosofía escolástica: de forma unívoca y en el mismo sentido no podía atribuirse el «ser» a Dios y a una creatura. Si fuera así, la creatura poseería en su condición algo «divino», y, se pensaba, pudiera caerse en el panteísmo. La solución fue establecer la analogía en la predicación del concepto de ser. La cuestión de la «analogía del ser» fue una de las grandes cuestiones discutidas durante siglos por suaristas y tomistas. Los suaristas defendían la llamada «analogía de atribución intrínseca» que consistía en decir que, en efecto, todo ser (incluido el mismo Dios) realizaba intrínsecamente las propiedades de clase del concepto ser (atribución intrínseca), pero esto no era óbice para que cada ser realizara estas propiedades de forma específica y propia. Así, Dios tendría «ser», pero realizado de una manera propia, perfectísima, distinta de la forma de realizar el ser en las creaturas. En cambio, los tomistas defendían la llamada «analogía de proporcionalidad» que consistía en defender, según su ontología dualista, que, como antes hemos explicado, el primer transcendental de la mente no es el puro «ser», sino el «ente», en cuanto abarca esencia y existencia (se atribuye el ser de una determinada esencia, así, el vegetal, el animal, el hombre, tienen el ser de la perfección propia de la forma vegetal, animal o humana). En este sentido, Dios tenía el ser propio de la esencia divina, siendo así que en Dios la esencia y la existencia se identifican. Los tomistas definían a Dios como aquel ser cuya esencia se identifica con la existencia (no hay «esencia» limitante). En cambio, los suaristas definían a Dios como el Ipsum Esse Subsistens.

El ser y las nociones transcendentales. Ahora bien, si estamos hablando de un "paquete conceptual» que correspondería a la noción universal de «ser», ¿en qué consiste ese paquete? A esto responde la doctrina escolástica sobre el ser y las nociones transcendentales que Suárez resolvió dentro de la lógica de su sistema. "Nociones transcendentales» son todo aquello que se afirma bajo el concepto transcendental de ser. El ser universal, por tanto, se despliega en sus transcendentales. Para Suárez son tres: el unum, el verum y el bonum. Los explica ampliamente en sus Disputaciones Metafísicas. El unum consistiría en la unidad armónica entre todas las propiedades y notas físicas de un ser (en la creatura sería la armonía de su constitución y en Dios la armonía de aquellas propiedades ontológicas de la Divinidad, que nos son desconocidas). Este unum entraría en relación (es decir, prefiguraría, a la altura de la

serían la fuente causal del conocimiento universal y necesario (y de la ciencia como tal). Esta manera de pensar se opondría a Suárez, al empirismo y a su teoría inductiva de la ciencia, así como, al enfoque empirista que acabará siendo básico en la ciencia moderna. 
filosofía en el tiempo de la escolástica) con la sustantividad zubiriana como «sistema cíclio y clausurado de notas» y, en general, con la idea de estructura en la epistemología y ciencia moderna. El verum afirma que todo ser (por su «unidad») lleva atribuida la noción transcendental de que «podría ser objeto de una intelección», es decir, sería cognoscible. Esta verdad del ser tiene diversas modalidades: verdad ontológica (la ontología «unitaria» del propio ser), verdad lógica (la adecuación entre la representación y las cosas reales), verdad moral (la adecuación entre el contenido de la mente y lo que se dice) y verdad formal (dentro de un sistema lógico). Por fin, el bonum diría que todo ser supone una riqueza y que merece ser asumido, el ser merece ser «sido», o «vivido» si hablamos de seres vivos.

Primeros principios. En la filosofía de Suárez tiene una especial importancia su doctrina de los "primeros principios», mucho mayor que en el tomismo. Los primeros principios son cuatro: el de No-contradicción, el de Razón Suficiente, el de Causalidad y el de Finalidad. Tienen también, en parte, origen aristotélico. Los dos primeros son la formulación en forma de principio del unum como transcendental. Decir unidad y armonía en el ser significa excluir entre sus notas la no-contradicción. En el fondo, la razón suficiente está también implicada en la suficiencia del ser de Parménides (que pasa a la idea platónica y a la forma aristotélica). El principio de causalidad responde al tratado de las causas aristotélicas. El principio de finalidad es el de menos tradición griega. Estos principios rigen, al mismo tiempo, el modo de ser real de las cosas y las operaciones del conocimiento humano (y de su lógica).

El principio de razón suficiente. Este es, para Suárez, además del principio de no-contradicción, el principio más importante. En el fondo podría decirse que la intuición de Parménides sobre la suficiencia del ser (absolutez) se posa sobre el principio de razón suficiente de Suárez. Para el tomismo puro la suficiencia del ser estaba dada en perfección de las formas (que, si no estuvieran unidas a la materia, serían de por sí el ser perfecto estable y permanente de sus formas). Para Suárez, el conocimiento del ser que se ha construido desde la aprehensión del singular, a través su universalización, analogía y transcendentales, es lo que pone en condiciones a la razón humana de entender que el ser debe tener una razón suficiente de sí mismo.

Búsqueda inductiva de la suficiencia: la contingencia. Pero, ¿dónde situar la suficiencia del ser que el hombre constata en la experiencia de los singulares? La respuesta depende de la previa constatación, por experiencia, de que los singulares que constituyen el mundo, en ningún caso poseen en sí mismos la suficiencia. ¿Por qué? Pues simplemente porque la experiencia nos muestra que surgen en un momento del tiempo el mundo y desaparecen después; por tanto, no puede atribuírseles la suficiencia. Los seres «contingentes» son aquellos que tienen ser, pero no poseen en sí mismos la suficiencia del ser. El mundo en su conjunto es un agregado de seres y, en consecuencia, el mundo como conjunto (así pensaba la escolástica suarista) debe ser pensado también como 
contingente. Por tanto, puesto que la suficiencia debe estar fundada en algún sitio, y no se da ni en los singulares ni en el mundo como conjunto, entonces, ¿dónde colocar la suficiencia de la que deben depender los seres contingentes? La respuesta de Suárez, en principio, es postular la existencia de un Ipsum Esse Subsistens, a saber, postular la existencia de un ser que debe ser suficiente en sí mismo. ¿Cómo debería pensarse la naturaleza de ese Ipsum Esse Subsistens? Aquí entran los razonamientos de la metafísica suareciana que concluyen en la afirmación de que debería identificarse con Dios. El Ipsum Esse Subsistens debería fundar el ser de todos los demás seres contingentes y del mundo en su conjunto, por tanto, esto no podría hacerse sin ser creador y sostenedor en el ser de los seres contingentes. No cualquier Ipsum Esse Subsistens podría fundar el universo contingente. Para poder hacerlo debería ser creador y esto lleva a la idea de Dios. La idea de suficiencia se refiere así en Suárez a la causalidad y Dios aparece como la Causa Primera que pone en movimiento el ser contingente del universo ${ }^{17}$.

Acción creadora de la Causa Primera. Suárez ve a Dios contemplando todas las esencias posibles, antes de la creación. El tema de los «posibles» es clásico en la metafísica suarista. Podrían dar lugar a diversas constituciones de los seres. En su plan creador Dios decide crear esencias finitas en un mundo que es también finito y contingente. Su finitud no depende de una limitación de la forma por la materia (en una ontología dualista), sino que son esencias limitadas por creación (que tienen su fundamento dependiente de la suficiencia creadora de Dios). Dios crea esencias diferenciadas que fundan su individuación. Entre los seres creados y el mismo Dios existe, pues, una analogía que, como antes decíamos, puede entenderse como «atribución intrínseca». Por otra parte, para Suárez los pares de conceptos materia-forma, esencia-existencia, acto-potencia, no deben entenderse en un supuesto dualista (como hace el tomismo), sino como la misma forma de ser natural de los seres, unitaria, que hace posible que la razón distinga, por pura razón, aspectos de los seres finitos creados como son la materia, la forma, la esencia, la existencia, la actualidad y la potencialidad. Así, en este contexto lógico, Suárez no tenía por qué atribuir a la pura materia la condición ontológica de no-ser en absoluto, o pura potencialidad para ser. Al contrario, atribuye a la materia prima una cierta condición de ser (no comparable a la riqueza de ser de las formas finitas creadas por Dios). Frente a la distintio realis, distinción real, entre materia y forma, Suárez introduce el importante concepto de distintio rationis cum fundamento in re. Igualmente, cuando Suárez habla de unión substancial no lo hace en el sentido tomista.

17 En la identificación, eo ipso, del Ipsum Esse Subsistens con Dios, aunque medie una argumentación racional, propia de la escolástica, es donde se produce la divergencia de Suárez con la ciencia y la filosofía moderna. A ello nos referimos en la nota siguiente. 


\subsection{Suárez: su significación histórica, epistemología y metafísica}

Por tanto, la razón que conoce la realidad se enfrenta primeramente con el singular sensible que se entiende como una "esencia objetiva», con la «aptitud para ser» que ello comporta, y como existencia. Esta primera aprehensión del singular sensible tiene la suficiente coherencia, unidad y armonía objetiva como para fundar una primera estabilización de la mente; sin embargo, más tarde, sin precisar cuándo, el conocimiento más amplio del singular conducirá a la problematización del movimiento que llevará a la idea de contingencia y a Dios, a través del principio de razón suficiente. Por el proceso abstractivo de la mente, in representando, no in essendo, se forman los conceptos universales por abstracción y generalización, por selección de cualidades y clases. El concepto de ser, que se hace también universal por el mismo proceso inductivo-abstractivo, lleva por sí mismo la afirmación de las «nociones transcendentales» que están siempre dadas en el conocimiento del ser: la unidad (esta es la nota más importante que muestra la «aptitud para ser»), la verdad y la bondad. Los primeros principios se derivan de los transcendentales del ser por análisis de extensión transcendental: el principio de no-contradicción, el de razón suficiente, el de causalidad y el de finalidad; el tratado de las causas puede construirse también como una extensión de estos principios. Apoyándose en el instrumento conceptual que se ha conseguido con todo esto se enfrenta entonces la razón con el análisis del movimiento (con la deficiencia ontológica que esto lleva consigo), con la transitoriedad y la finitud de los seres, la contingencia, y la muerte. Así nace el juicio de contingencia: el ente mundano no tiene en sí mismo la razón suficiente de su existencia. Pero el principio de razón suficiente, aplicado necesariamente al ser (desde Parménides), obliga a inferir donde puede estar radicada la suficiencia de la que dependen los seres contingentes. Esto lleva a la afirmación de la existencia fundante del Ipsum Esse Subsistens, estableciéndose la relación fundamente entre ser contingente y Ser Absoluto ${ }^{18}$. El análisis del movimiento, además,

18 Suárez postula la necesidad, por tanto, de situar en algún sitio la «suficiencia del ser» (según la lógica de Parménides). Para él, es fácil argumentar que esa suficiencia exige afirmar la existencia de un "ser divino», al que se atribuiría la suficiencia y el fundamento del ser. Todos los seres son contingentes. El mundo no es sino un conjunto (agregado) de seres contingentes que, en consecuencia, debe ser considerado él mismo como contingente, exigiéndose entonces colocar la suficiencia en algo que no sea "mundo» como tal (transcendente). Para la ciencia moderna, en cambio, no es admisible este razonamiento suareciano. La ciencia estaría de acuerdo en que los estados del mundo que observamos por experiencia son "contingentes». Admitiría también que la existencia real del universo exige que se sitúe en un fondo de suficiencia absoluta: si no fuera así no existiría o se habría de-construido, hasta desaparecer. Por tanto, no creo que para la ciencia sea difícil postular una «suficiencia» atribuible al universo (e incluso, un «Ipsum Esse Subsistens», ya que se trata de terminología). Sin embargo, la gran cuestión es a quién o a qué debe ser atribuida esa "suficiencia» en la que se apoya el universo. La suficiencia podría estar fundada en Dios, como afirman los sistemas teístas tradicionales, como en el de Suárez. Pero la suficiencia podría también estar fundada en un puro mundo sin Dios. Que los estados 
ha dado lugar a la formulación suarista de la teoría acto-potencia en la que el movimiento, siguiendo la tradición aristotélica, se entiende también como el acto del ser en potencia en cuanto está todavía en potencia. Supuesta ya la existencia de Dios, al que se ha llegado a través del Ipsum Esse Subsistens, como ser fundamental, se justifica entonces, por la vía de la creación, la limitación esencial de las creaturas, su individuación, etc. Es decir, se reconstruyen los principales temas o tópicos del pensamiento escolástico tradicional, pero sin la necesidad de recurrir a los conceptos «duros» del tomismo.

\section{TOMISMO Y SUARISMO EN LA EVOLUCION DE LA ESCOLÁSTICA HASTA NUESTROS DíAS}

La escolástica, Santo Tomás y el tomismo fueron una filosofía medieval que hundía sus raíces en la tradición cristiana que venía desde el nacimiento de la patrística, al comenzar las relaciones con la cultura griega. El mundo medieval, y la cultura cristiana, sufrieron una conmoción profunda al producirse, poco a poco, el cambio cultural que lleva desde el medievo al renacimiento. El mismo tomismo era consciente del problema que le había nacido con el nominalismo en el siglo XIV, y que se acrecentó en el siglo XVI. La ciencia y la filosofía moderna, su espíritu empirista que fructificará en el siglo XVII, tras el preludio del sensismo del siglo XV, se sumarán a las orientaciones del pensamiento que eran incompatibles con el tomismo. El tomismo era consciente de esto y se explica así su intento de reformularse, para reforzar la lógica de su argumentación filosófica, en su síntesis sistemática del tomismo puro, en los siglos XV-XVI.

En esta situación, no cabe duda de que el sistema escolástico de Francisco Suárez representó la verdadera y más profunda revisión de la escolástica, en una línea que suponía adaptarse a la forma de pensar de una cultura naciente. En todo caso, hay que tener en cuenta la situación de Suárez en su tiempo. Un tiempo difícil, en el que se vigilaba con lupa la ortodoxia católica, y fácilmente se podía ser objeto de sospecha, e incluso de acusación de herejía. La posición de Suárez era difícil. Por una parte, debía decir lo que en conciencia creía que debía decir, y esto suponía una crítica radical del tomismo, que constituía hasta entonces la doctrina segura y, en alguna manera, tutelada por la iglesia. Pero, por otra, debía decir las cosas de tal manera que diera la impresión de que la nueva doctrina era, en el fondo, una interpretación, no sólo legítima sino correcta, de Santo Tomás. Suárez se consideraba a sí mismo, aunque parezca sorprendente, un tomista. Así, la estructura de conjunto de la filosofía-teología

del universo, momentos de su evolución en el tiempo, sean contingentes, no supone que la estructura misma del universo, en cuya evolución todo se transforma y nacen esos estados contingentes, transitorios, sea también como tal «contingente». El universo podría ser, como ya vio Heráclito, en una de sus sentencias más importantes, «fuego eternamente viviente que se crea y se destruye según medidas». 
de Suárez responde a la estructura clásica de la escolástica (y, por tanto, del tomismo). Los temas, tópicos o lugares comunes, de Suárez son también los de la escolástica. En mi opinión, los intelectuales católicos de su tiempo (tomistas por lo general y, por descontado, escolásticos) no acabaron de darse cuenta de la novedad radical que representaba el pensamiento de Suárez. El mismo Suárez probablemente procuró no dar facilidades para que lo entendieran. Aun dentro de la confusa percepción del sistema de Suárez, no obstante, las críticas fueron constantes y descalificadoras. Para los escolásticos «conservadores»el sistema de Suárez estaba lleno de «errores», había cedido innecesariamente a la orientación del nominalismo (lo acusaban de nominalista) y, por último, era una mala e incorrecta copia de Santo Tomás. Lo único que tenía de bueno era, en el fondo, de Santo Tomás.

\subsection{El sistema de Suárez hasta el siglo $X X$}

En todo caso, es un hecho que pertenece ya a la historia de la filosofía que el sistema de Suárez pasó a jugar un papel de protagonismo estelar en los siglos siguientes, llegando a ser denominado como la Segunda Escolástica. Sería la interpretación de la escolástica que trató de adaptarse al estilo de pensamiento "empirista», consecuencia del nominalismo y de la ciencia, que estaba naciendo en la modernidad. Era la escolástica de una nueva época. Desde el siglo XVII, cuando se extendió la influencia de Suárez en sectores importantes de la iglesia católica, hasta entrado el siglo XX, han coexistido los tres grandes sistemas escolásticos: tomismo (seguido por la mayoría, especialmente por los dominicos), el escotismo (seguido en minoría por los franciscanos, y, en mi opinión, más cercano al suarismo) y el suarismo (la segunda escolástica que fue seguida por la mayor parte de los jesuitas, y por otros).

Es difícil entender que Suárez pudiera llevar a cabo su obra filosófica sin el apoyo institucional de los jesuitas, cuya influencia en la educación europea fue decisiva en los siglos XVII y XVIII. En Roma, Italia, Francia, Italia, Bélgica, España, a través de la obra docente de los jesuitas, se fue extendiendo más y más la influencia del sistema de Suárez. No queremos decir con esto que fuera dominante, ya que el tomismo siguió siendo la filosofía/teología básica de referencia en el catolicismo. Cabría pensar, en principio, que la influencia de Suárez debiera haberse extendido todavía mucho más, puesto que, al fin y al cabo, representaba una versión más moderna de la escolástica, más armónica con el espíritu del mundo moderno. Pero no fue así. ¿Por qué? Pienso que, en definitiva, porque la confusión filosófica era muy grande: no se entendía bien qué era la modernidad y lo que significaba, no se entendía bien el pensamiento de Suárez que era algo nuevo, y por ello sospechoso, y, además, era muy fuerte la inercia del pensamiento antiguo, el tomismo, que representaba la tradición y debía ser tutelado.

Por tanto, hasta entrado el siglo XX, el suarismo mantuvo, durante siglos, una importante presencia en el mundo intelectual católico. En los años cincuenta y sesenta del pasado siglo, en España, la mayoría de los centros 
de estudios de los jesuitas seguían siendo, en conjunto, preponderantemente suaristas. Sin embargo, el hecho es que el suarismo fue siendo poco a poco arrinconado por las corrientes modernas del tomismo, que estaban siendo promovidas precisamente por jesuitas. El proceso que llevó a la predominancia del tomismo en el siglo XX tuvo su origen en la configuración de la filosofía escolástica "crítica», en la segunda parte del siglo XIX y en la primera del XX.

Nace la escolástica "crítica» a fines del XIX. La filosofía crítica de Kant jugó un papel de gran importancia en la evolución de la escolástica. A fines del XIX se produjo el movimiento europeo de «vuelta a Kant» y su influencia fue en ese tiempo extraordinaria. La escolástica se vio obligada a abrirse a la filosofía del tiempo para construir también su propia «filosofía crítica» frente a Kant. Nació así la «escolástica crítica» que introdujo en el curriculum escolástico una nueva asignatura que se denominó precisamente «crítica». Esta «crítica» tenía una finalidad definida: mostrar que por los sentidos se tenía acceso a un mundo externo de objetos que la razón podía conocer y pensar sobre ellos (se refutaba el idealismo y el apriorismo de Kant ${ }^{19}$.

Kant, por tanto, era un autor que había tratado de poner coto a las pretensiones abusivas del conocimiento. Durante siglos la filosofía escolástica había permanecido al margen de cuanto se hacía fuera de ella. Coincidió que, a fines del XIX, buscó el diálogo con la filosofía civil para justificarse y ganar prestigio: pero en ese tiempo la filosofía burguesa tenía a Kant como autor de máximo prestigio. El problema era, pues, que Kant negaba precisamente que fuera posible lo que la filosofía escolástica estaba pretendiendo durante siglos: conocer racionalmente el mundo objetivo y justificar la existencia real de Dios. Así, el problema fundamental de la filosofía «crítica» escolástica consistió en demostrar que el hombre podía conocer realmente el mundo objetivo, formar

19 Kant, en la segunda mitad del XVIII, aportó una nueva teoría que era racionalista, pero corregía al racionalismo. El conocimiento se producía por la experiencia o sensación (aposteriori), pero las sensaciones eran organizadas por ciertos principios apriori que pertenecían a la razón. Pero, en contra de la teoría racionalista, estos principios no producían conocimiento sin la experiencia (o sea, sólo cuando organizaban las sensaciones, aunque ellos eran apriori); junto a esto tampoco se podía afirmar que estos principios coincidieran con la realidad verdadera del mundo en sí mismo. Sólo podíamos afirmar que estos principios apriori tenían un valor funcional o formal (servían para organizar la experiencia y en consecuencia para vivir con eficacia). Esto supuesto, Kant describió el conocimiento matemático, físico y metafísico, deduciendo los factores apriori y aposteriori que lo producían. La matemática y la física eran posibles como ciencia. La metafísica no: estaba formada sólo por juicios que analizaban la idea apriori de Dios, del Alma o del Mundo. Pero no podíamos saber si los principios apriori de la matemática, de la física o de la metafísica (universales y necesarios en toda la especie humana) coincidían con la realidad en sí misma (nouménica). No sabíamos, por tanto, si Dios existía. Kant llegó sólo por el estudio del conocimiento moral a la existencia de Dios; pero no como resultado del análisis racional del mundo objetivo. Por la razón natural objetiva, por tanto, el hombre quedaba siempre encerrado en la pura formalidad de sus principios apriori (inmanencia). Dios no podía ser argumentado por la razón natural (razón pura), ya que cosmología, psicología racional y teodicea sólo eran puro discurso apriori, al que no se podría atribuir congruencia con la realidad en sí misma. 
conceptos que correspondían a la realidad en sí misma y conocer la verdad. Numerosos filósofos escolásticos dedicaron su esfuerzo a mostrar la validez del conocimiento objetivo para salir del «inmanentismo» kantiano.

Una larga lista de autores escolásticos ingeniaron diversos caminos para llegar siempre al mismo final: justificar la validez del razonamiento objetivo. Se extraía conocimiento y se sacaban las inferencias necesarias. Podemos recordar al cardenal Mercier, a Gardeil, Garrigou-Lagrange, Picard, Balmes, pero, sobre todo, a quienes, a través de Rousselot, llevan a los comienzos del neotomismo transcendental con la filosofía de Joseph Marèchal y de Karl Rahner. La interpretación que estos autores hicieron del tomismo estuvo inspirada en la obra filosófica (no escolástica) de Maurice Blondel ${ }^{20}$.

\subsection{Una nueva interpretación del tomismo: el neotomismo transcendental}

La antropología metafísica de Blondel. Kant había invalidado el uso de la razón objetiva de la escolástica como resultado del estudio del conocimiento. La crítica escolástica pretendió refutar la teoría del conocimiento kantiana. Pero un filósofo cristiano, no escolástico y que no formaba parte del clero, ensayó una vía apologética (orientada a mostrar la existencia de Dios) que se fundaba como Kant en una reflexión sobre el hombre. Era una antropología, que se situaba de principio en la inmanencia humana, pero que concluía mostrando que el hombre no podía entenderse sin ponerlo todo él en función de una realidad metafísica que se debía identificar con Dios. La fenomenología de la inmanencia humana (sobre todo el sugerente estudio de la volonté voulante y de la volonté voulu, o sea, del desajuste entre el deseo humano y la realidad frustrante que constituía la vida real) exigía como condición de posibilidad (como aquello que la hacía posible) entender al hombre como un ser cuya acción, cuyo pensamiento y cuyo ser, estaba todo él encaminado hacia un «infinito atrayente» que se identificaba con Dios. La forma blondeliana de decirlo era afirmar que la Transcendencia era la condición de posibilidad de la forma en que el hombre advertía su propia inmanencia. No era, posible entender al hombre sin postular la existencia real de la Transcendencia ${ }^{21}$.

Neoescolástica tomista transcendental: Maréchal y Rahner. Frente a la vía objetiva de la crítica escolástica para refutar a Kant (que buscaba justificar el valor objetivo del conocimiento), Blondel había abierto, pues, una vía argumentativa que se fundaba en el hombre: en el análisis antropológico. En el primer tercio

20 Para el estudio de los principales autores de la epistemología tomista que nace en el XIX, con el objetivo de refutar el «idealismo transcendental» de KANT (los mencionados Balmes, Mercier, Picard, Garrigou-Lagrange, Gardeil, Rousselot (301 ss), Joseph de Vries (suareciano) y otros, incluido el mismo Joseph MARĖCHAL (p. 263 ss), me remito a la obra: VAN RIET, G., L'epistemologie thomiste. Recherches sur le problème de la connaissance dans l'ecole thomiste contemporaine, Institut Supérier de Filosophie, Louvaine 1946.

${ }^{21}$ Para seguir al Blondel más vivo y profundo debemos referirnos a L'Action, de 1893. 
del siglo XX muchos filósofos cristianos — sobre todo de habla francesa-vieron en Blondel una filosofía nueva y progresista que apoyaron Dumery y Rousselot, por ejemplo. En esta línea, el jesuita belga Joseph Maréchal fue el creador de una nueva interpretación del tomismo clásico en conexión con la filosofía de Kant, que hoy conocemos como neotomismo transcendental. Marechal siguió a Blondel, pero quiso pensar también a partir de Kant, al mismo tiempo que permanecía en el tomismo. En esencia, propuso una reconstrucción de la crítica de la razón pura. Kant había hecho la crítica transcendental (el estudio de los principios apriori y aposteriori) de la matemática, de la física y de la metafísica. Pero había olvidado hacerla del hecho de la «afirmación ontológica» (del hecho de que todo conocimiento era siempre conocimiento del ser, en la matemática, en la física y en la metafísica). Por tanto, el análisis transcendental kantiano de la afirmación ontológica le permitió concluir que la razón humana funcionaba ejerciendo un nuevo principio apriori no conocido por Kant: la apertura al Ser Absoluto, ilimitado, universal. Todo juicio era siempre una concretización del ser universal (recuérdese la teoría tomista de la prevalencia del universal). Ahora bien, según Maréchal, con inspiración en Blondel y en el finalismo de Rousselot, el conocimiento del ser era una tendencia finalística que exigía la existencia real del correlato de la tendencia (y no ser un mero principio formal o funcional al estilo kantiano). La razón pura kantiana (el conocimiento del mundo objetivo) suponía, por tanto, afirmar la existencia real de Dios como correlato real de la naturaleza finalístico-tendencial del conocimiento humano ${ }^{22}$.

Esta misma manera de pensar fue defendida por Karl Rahner, sobre todo en su obra básica Espíritu en el Mundo. A través de su estudio de la sensibilidad, la abstractio y la conversio ad phantasmata (que aquí no explicamos) defiende las mismas ideas que Maréchal, del que se considera seguidor. El tomismo de Rahner es el «tomismo clásico» en toda su radicalidad (vg. en el concepto de la «materia» y de la «forma», presentados en una perspectiva transcendental). El conocimiento no es inteligible sin aceptar la apertura transcendental, apriórica e inobjetivable, al Ser Absoluto, que debe aceptarse como realmente existente, por la misma razón que en Maréchal, a saber, por ser el necesario fundamento real de la apertura finalística del conocimiento apriori al ser-en-absoluto divino. Esta apertura sería parte de una constitución ontológica previa (apriórica en el sentido kantiano) que se haría siempre presente en el conocimiento. Rahner, que concibe su metafísica como una «metafísica del conocimiento finito según Santo Tomás de Aquino», parte de la interpretación de un artículo de la Summa Theologica y en todo caso hace una síntesis entre el enfoque kantiano y los principios del tomismo clásico ${ }^{23}$.

22 Maréchal, J., El punto de partida de la metafísica, vol. V, Gredos, Madrid, 1959.

23 Rahner, K., Espíritu en el mundo, Herder, Barcelona, 1963. Su punto de partida: p. 73. El conocer único como sensibilidad, presentia mundi: p. 128, 95, 162. El conocer único como pensar: oppositio mundi: 185-86, 172; El conocer único en su unidad misma: conversio ad phantasmata: cap. IV. 


\subsection{Tomismo y suarismo en la segunda mitad del siglo $\mathrm{XX}$}

El suarismo, como decíamos, se siguió cultivando hasta entrado el siglo XX en numerosos centros de estudios, principalmente de los jesuitas. Pero no tuvo una renovación importante. Seguía haciéndose suarismo como siempre se había hecho en los siglos anteriores. Frente a este continuismo suarista, el tomismo, en cambio, supo hallar vías de renovación importantes que le dieron un halo de modernidad. Nos referimos, claro está al tomismo transcendental. En los años cincuenta, sesenta y setenta del siglo XX, la promoción de este neotomismo se hizo constante, hasta el punto de que más y más profesores, avalados por el prestigio de Rahner, abandonaron el tomismo clásico y se pasaron al tomismo transcendental kantiano. La impresión era que este tomismo se armonizaba con autores básicos del pensamiento moderno, ante todo con Kant, y que, por ello, se rompía con el aislamiento de la filosofía escolástica.

Sin embargo, esta eventual «modernidad» a través del tomismo transcendental era engañosa, al menos desde mi valoración. El tomismo transcendental, en efecto, se funda en Kant, pero Kant no es un autor que sea garante de la modernidad. En su tiempo jugó un papel, sin duda, y se mantuvo hasta final del siglo XIX. Pero a la ciencia moderna le es muy difícil admitir la esencia de la antropología kantiana: a saber, que existen unos principios a priori en el sentido racionalista (que no tienen relación con la experiencia y no se derivan de ella) que son los que organizan los datos sensibles y constituyen el conocimiento. Para la ciencia moderna la mente humana se construye aposteriori en función de la experiencia de los seres vivos en el proceso evolutivo. Por otra parte, el tomismo de Rahner, de forma evidente, admite los principios ontológicos del tomismo puro y es dualista. Aquí también chocamos con la modernidad de la ciencia que entiende el universo desde un paradigma monista, muy distinto al paradigma dualista que pasó al cristianismo desde las filosofías griegas de Platón y de Aristóteles.

Tal como hemos venido exponiendo, el pensamiento de Suárez es, en el fondo, más moderno que el tomismo. Desde luego más moderno que el transcendental, ya que este, además del problema del dualismo, suma el problema del absoluto apriorismo de los principios de la razón. Sin embargo, el suarismo no ha tenido, a lo largo del siglo XX, una actualización que permitiera entender su armonía con el pensamiento moderno. En este sentido, la única gran aportación en la línea del suarismo ha sido la filosofía de Xavier Zubiri. No es que Zubiri sea «suarista». En absoluto. Pero sí es verdad que la obra de Zubiri representa una nueva formulación de las grandes intuiciones de Suárez y, por ello, puede decirse que en la filosofía española existe una continuidad que se proyecta desde el pensamiento de Suárez, de hace varios siglos, sobre el pensamiento actual de Zubiri. A ello nos referimos a continuación. 


\section{Actualización de Suárez en la filosofía primera de Xavier Zubiri}

Debemos primero aclarar el alcance de este título. No queremos decir que Zubiri sea suarista o que el conjunto de su obra pretenda ser una exposición del sistema de Suárez. En absoluto. La filosofía de Zubiri ha sido construida por Zubiri de una forma original que expone solo una visión personal que ha sido concebida para responder las grandes preguntas filosóficas ${ }^{24}$.

Siendo esto así, no podemos dejar de admitir que Zubiri conocía perfectamente el sistema de Suárez y su significación en la evolución de la escolástica. Zubiri conocía la teoría básica de Suárez: la prevalencia del singular en el proceso cognitivo. No cabe duda de que conocía que lo conocido radicalmente en el singular era su «esencia objetiva», o «aptitud para ser», tal como hemos expuesto. A su vez, la «esencia» era un conjunto de notas, rasgos o propiedades sensibles, objetivas, que se presentaban formando una unidad armónica, no-contradictoria. Pero esa «esencia» no sólo tenía notas sensibles, sino que también podría ser objeto de una atribución intrínseca del concepto universal de ser: situados ya en el ser, por extensión, se llegaba entonces a la noción transcendental de «unidad» (unum), conectada ya directamente con la inferencia de los primeros principios, ante todo con la no-contradicción, con la razón suficiente y con la causalidad. Todo esto lo debía conocer perfectamente Zubiri. Así debemos suponerlo fundadamente. Por tanto, Zubiri sabía que el sistema de Suárez, al preguntarse cuál era el origen del conocimiento humano y de la razón (hoy diríamos de la mente), lo había establecido en el momento en que se aprehendía por los sentidos una «esencia objetiva» (que estaba ahí y se "presentaba» ante la capacidad sensitivo perceptiva del hombre), que se mostraba también «inteligible» porque era una esencia armónica, coherente en todas sus notas sensitivas, no-contradictoria, y que por ello mismo mostraba también una «aptitud para ser». Las «esencias objetivas» tenían "ser» (y fundaban inductivamente el concepto de ser universal) porque tenían la «unidad»necesaria para poder existir (unum $)^{25}$.

${ }^{24}$ La bibliografía completa de Xavier Zubiri puede verse en la web de la Fundación X. Zubiri. Me refiero aquí solo a obras de referencia para nuestro comentario en este artículo. Naturaleza, Historia, Dios, Alianza, Madrid, 1987; Sobre el hombre, Alianza, Madrid, 1986; Sobre la esencia, Sociedad de Estudios y Publicaciones, Madrid, 1963; naturalmente el volumen primero de la trilogía: Inteligencia sentiente. Inteligencia y realidad, Alianza, Madrid, 1980; También: «Notas sobre la inteligencia humana», en: Asclepio, vol. XVIII-XIX, 1956-57, 341-353; «El hombre y su cuerpo», en: Asclepio, vol. XXV, 1973, 1-15; «El hombre, realidad personal», en: Revista de Occidente, abril 1963, 5-29.

25 Es sabido que Zubiri, cuando publicó Sobre la Esencia, tuvo numerosas críticas, la mayoría de círculos conservadores que velaban por la doctrina tomista. También hubo críticas en ámbitos de filosofía "progresista», que hasta hacían chistes con ocasión de expresiones zubirianas. Zubiri se vio afectado por la dureza de las críticas. En este tiempo tuvo el apoyo personal, y el respaldo público, del jesuita José Hellín, probablemente el mejor suarista español de su tiempo. Ya antes ha sido mencionado. En las conversaciones entre Hellín y Zubiri debió estar flotando la convergencia de orientación entre el propio Zubiri y 
Ahora bien, ¿cuál es la intuición básica, radical, en la que se funda la «filosofía primera» de Zubiri? Es muy semejante a la de Suárez. Para Zubiri, el orto, la génesis de la razón humana (de la mente humana) se produce en el momento en que el hombre comienza a aprehender los estímulos sensibles como «realidad». El término realidad es propio de Zubiri, pero designa una aprehensión similar a la aprehensión del singular en Suárez. Realidad es algo que está ahí frente al hombre, con su independencia y autonomía, patente como un «de suyo», dice Zubiri, que consiste objetivamente en un sistema cíclico y clausurado de notas (estas notas son manifestativas, fenoménicas). Es, en terminología zubiriana, un «sistema sustantivo». El ser, pues, se predica de esos sistemas sustantivos, previamente aprehendidos como tales. Precisamente por estar constituidos por sistemas de notas físicas (sensibles) coherentes en sî mismas, las cosas sustantivas pueden conocerse como ser (la aptitud-para-ser de Suárez). Zubiri distingue entre «realidad» y «ser» de una forma nueva no conocida por la escolástica ni por Suárez. La realidad es el sustantivo, así como el ser es el verbo que designa la acción radical de mantener la propia realidad sustantiva en el curso del tiempo. En todo caso, no deja de ser sugerente que Zubiri nombre los sistemas sustantivos como «esencia»; precisamente el mismo término usado en la tradición suarista.

\subsection{Zubiri como actualización de Suárez}

Según lo dicho, Suárez y Zubiri mantienen posiciones similares: en Suárez la aprehensión del singular, de la esencia objetiva, previa al ser, y en Zubiri la aprehensión del sistema sustantivo de notas de la realidad, también previa al ser que supone la realidad de lo sustantivo. Sin embargo, Suárez construye su argumentación a principios del XVII y Zubiri, en cambio, piensa en pleno siglo XX. Obviamente, Zubiri entiende su idea de lo sustantivo a la altura de los resultados de la ciencia y de la filosofía en nuestro tiempo. La intuición compartida con Suárez es presentada por Zubiri en un marco de información y de argumentación mucho más completa y compleja que la que pudo ser alcanzada por Suárez en su tiempo. Por ello decimos que Zubiri puede representar una actualización del pensamiento de Suárez. Lo que Suárez dijo en su tiempo ha sido actualizado hoy por Zubiri de una forma mucho más rica y potente.

\footnotetext{
Suárez. No deja de ser significativo que el libro fundamental de Zubiri fuera titulado Sobre la esencia, siendo precisamente la esencia el tópico más importante de la epistemología de Suárez. Permítaseme una referencia personal: cuando comenzaba a estudiar filosofía estaba rodeado de tomismo transcendental, entonces la corriente más prestigiada (como todavía sigue siendo en amplios círculos católicos); sin embargo, tuve siempre la persuasión de que Suárez seguía una línea más correcta y actual que el tomismo. Cuando conocí el pensamiento de Zubiri encontré el punto de apoyo para dejar de lado definitivamente la confusión y el peso del tomismo dominante. Mi evolución de aquel tiempo la he explicado en una entrevista que me hicieron Jordi Corominas y Joan Albert Vicens, publicada como Conversaciones sobre Xavier Zubiri, PPC, Madrid, 2008, 213-228. Estas conversaciones complementaron su biografía de Zubiri: Xavier Zubiri, la soledad sonora, Taurus, Madrid, 2005.
} 
Para entender lo que Zubiri quiso hacer con sus propuestas epistemológicas, antropológicas y filosóficas, cabe recordar una inquietud de su tiempo. Si consideramos que, antes del hombre, solo había animales, homínidos, y se admite el proceso evolutivo que lleva del animal al hombre, entonces se plantea una pregunta obvia: ¿qué pasó en la mente animal para que se convirtiera en humana? ¿Qué pasa en la mente de nuestra especie cuando comienza a ser específicamente humana? En definitiva, ¿cuál es la causa esencial del proceso de hominización? A fines del XIX y comienzos del XX una serie de grandes científicos y filósofos eran conscientes de que la metafísica antigua ya no era válida y se necesitaba reconstruir una filosofía de los tiempos modernos. Para ello había que reconstruir el itinerario de la razón humana, desde sus raíces, hasta llegar a situarse en la idea moderna del mundo. Se buscaba definir la «esencia humana» desde sus raíces. Bergson exploró la esencia humana en el proceso evolutivo creador. Husserl indagó el análisis de la conciencia para hallar la forma en que se construían las representaciones básicas de la mente. Alfred N. Whitehead intentó también establecer un nuevo acceso a la esencia humana desde la idea que la ciencia moderna tenía del mundo. Zubiri, y el mismo Ortega y Gasset, vivieron también esta inquietud.

La respuesta de Zubiri constituye el núcleo básico y radical de su sistema de filosofía. ¿Cuándo comienza la mente del hombre a ser humana? La respuesta de Zubiri consiste en decir: la mente animal comienza a ser mente humana cuando llega a estar en condiciones de aprehender los estímulos y objetos sensibles de una forma nueva, no dada en el mundo animal, que nombra como «aprehensión de realidad». Así, lo que Zubiri llama la «aprehensión primordial de realidad» es el cambio representativo que instala al hombre en su condición humana. Es una aprehensión «sentiente» de realidad, es una nueva forma de sentir: el animal siente desde la formalidad de la «estimulidad», pero el hombre siente desde la formalidad de «realidad». Así, el hombre es un «animal de realidad». Ahora bien, ¿cuál es la forma en que se aprehende sensiblemente la realidad, las cosas reales? La respuesta de Zubiri es definida: el hombre aprehende la realidad como «estructura» (conjunto de notas, relacionadas en una unidad resultante).

En alguna manera, la idea de la «esencia objetiva» de Suárez está reformulada en la moderna idea de realidad en Zubiri. Pero Suárez no se plantea ni el origen de la mente ni sitúa su epistemología en una dimensión evolutiva. Es una visión antigua de las cosas. Zubiri, en cambio, presenta su idea de «realidad» en el marco de los resultados de la ciencia moderna. Por esto decíamos que es una actualización del pensamiento de Suárez. Podríamos decir, aludiendo al título de este artículo, que una posible proyección de Suárez (actualizado) sobre nuestro tiempo podría estar dada en la filosofía de Zubiri.

En lo que sigue voy a ceñirme a una breve presentación de la teoría de la hiperformalización biológica de Zubiri porque en esta teoría es dónde podemos ver la forma moderna, argumentada por Zubiri en su perspectiva propia, en que podría hoy entenderse, en toda su fuerza, la teoría suareciana de la prevalencia del singular en el proceso cognitivo. 
Hiperformalización biológica. La teoría de la hiperformalización biológica representa, en efecto, un sistema de hipótesis referidas a los procesos más básicos y fundamentales, de naturaleza neurológica, que probablemente produjeron la hominización. En nuestra opinión, esta teoría toca con mayor profundidad las probables causas neurológicas - transformaciones del sistema nervioso- que produjeron nuevos estados psíquicos que permitieron la transformación del conocimiento animal en humano. Inspirándonos en Zubiri, pero ampliada e interpretada por nosotros, exponemos seguidamente la teoría de la hiperformalización biológica ${ }^{26}$. Puede servirnos de muestra, como decimos, para entender cómo Zubiri representa una sorprendente ampliación moderna del marco que justificaría hoy la explicación de la intuición germinal de la teoría del conocimiento - y metafísica— de Suárez.

\subsection{Fundamentos empíricos y teóricos de la teoría de la hiperformalización}

Esta teoría es un macroconstructo hipotético, una conjetura científica: un sistema complejo de suposiciones o hipótesis que, si se hubieran cumplido, explicarían cómo se ha producido la emergencia evolutiva del conocimiento. Sin embargo, estas hipótesis no son gratuitas, ya que hay un conjunto de hechos empíricos y teorías científicas que hacen altamente verosímil que las cosas sucedieran realmente tal como esta teoría supone. Estos hechos y teorías previas ya han sido establecidos en disciplinas científicas como la biología, neurología, epistemología, etología, psicología, etc. Por tanto, enumeramos primero, brevemente, estos fundamentos empíricos y teóricos.

1) Se supone básicamente la teoría emergentista. En ella, la función teleonómica de la sensación-percepción-conciencia (potenciada por la constitución del sujeto y de la atención) es la eficacia en el registro de la información sobre el medio y el desencadenamiento de respuestas; es, en definitiva, la conexión estímulo-respuesta. 2) La biología evolutiva nos muestra cómo se ha producido la complejización creciente del sistema nervioso y del sistema de los sentidos, a medida que ascendemos en la escala zoológica que conduce al hombre.

3) En etología se estudia la naturaleza funcional de la conducta animal en general por el método objetivo. Existen conductas apetitivas (en que el animal reacciona ante estímulos generados internamente; por ejemplo, el hambre) y conductas consumativas (el animal reacciona ante estímulos externos que le permiten satisfacer inmediatamente sus impulsos). En general, la conducta es toda actividad animal que se genera automáticamente en respuesta a ciertos signos o señales que hacen referencia a futuros estados biológicos, evitando el displacer y produciendo el placer. Es la conducta que llamamos signitiva o

26 Si interesara ampliar la síntesis que presento aquí sobre la teoría de la hiperformalización biológica de Zubiri, me remito a: MonSERRAT, J., La percepción visual. La arquitectura del psiquismo desde el enfoque de la percepción visual, Biblioteca Nueva, Madrid, 2008 (segunda edición), en especial al cap. XIV, 533-600. 
instintiva. La conducta signitiva es un modo complejo de expresar la función teleonómica de la conciencia, antes mencionada: detección de información (señales) y desencadenamiento automático de respuestas. En etología se estudia también la forma en que el animal manifiesta una conducta objetiva. Objeto es toda constelación de estímulos que se presentan ante el animal con cierta independencia, autonomía, unidad y frente a los cuales el animal reacciona también unitariamente. Hay, pues una conducta objetiva cuando inferimos que percibe objetos y reacciona unitariamente ante ellos, considerándolos un todo. Los animales superiores presentan ya un universo rico en objetos (por ejemplo, un perro integrado en la sociedad humana que percibe a su «amo» o a «la casa»); no así los animales inferiores (vg. un cangrejo de río) que sólo siente estímulos puntuales de presión, frío, calor, roce, etc.

4) Se constata, por tanto, una relación complejización-objetivación. Es decir, entre la complejización nerviosa y los sistemas perceptivos con riqueza de objetivación en el psiquismo animal. Las conductas más complejamente objetivas aparecen en zonas de la escala zoológica con sistemas nerviososensitivos también más complejos y desarrollados. La unidad de notas de los objetos en el mundo animal es, pues, un precedente de la «esencia objetiva» en la aprehensión del singular, según Suárez.

5) El estudio de los sistemas perceptuales nos los presenta como sistemas de formalización. Los sentidos son sistemas de formalización diseñados evolutivamente. Se entiende por formalización la capacidad puramente biológica de coordinar una gran cantidad de información puntual, procesándola hasta producir la experiencia perceptiva terminal de unidades coherentes con independencia objetiva (objetos). En la percepción visual, por ejemplo, la información de los diferentes puntos del espacio exterior se procesa diferencialmente hasta producir por mecanismos inconscientes la organización terminal de la imagen, que podría tener también un último ajuste organizativo por los efectos gestálticos. En esta organización terminal aparecen objetos claramente diferenciados, enfocados y delimitados con el entorno preciso de sus líneas, sombreados, colores, etc. Pero si el sistema biológico (neuronal) de procesamiento está alterado — no formaliza bien-, entonces se altera también el efecto final de organización de la imagen (es lo que pasa bajo la alteración producida por drogas). Los objetos ya no aparecen precisos y nítidos; sólo una mezcla de colores difusos en que ya no es posible percibir los contornos de las cosas, las distancias o sus precisas ubicaciones en el espacio.

6) Se constata también una cierta relación inversa entre los grados de formalización del sistema perceptual y los niveles de signitividad de la conducta animal. Así, a mucha formalización, poca signitividad; en cambio, para una especie animal de respuestas altamente signitivas, muy automáticas, detectamos escasos niveles de formalización.

9) El proceso evolutivo, además, ha producido animales en un estado que denominamos de hipercomplejidad psíquica. Es un estado que se describe en estudios etológicos. El sistema de señales que el animal es capaz de detectar (su etograma) es cada vez más complejo. Al mismo tiempo aumenta también 
la complejidad y el número de los programas de respuesta; la conducta de caza de un león, por ejemplo, es una conducta altamente compleja, muy distinta del simplismo reactivo automático-determinista de un paramecio o una ameba ante los estímulos detectados en un medio acuoso. Esta complejidad hace cada vez más difícil la conexión automática, signitiva o instintiva, de una cierta señal (o conjunción de señales al mismo tiempo) con alguno de los muchos programas de respuesta presentes en el repertorio de la conducta animal. El animal inferior es así altamente automático o signitivo. El animal superior, en cambio, con un psiquismo cada vez más hipercomplejo, parece exigir una nueva función psíquica para "ponderar» el sistema estímulos-respuestas. Esta función fuerza el protagonismo creciente del «sujeto psíquico». La aparición evolutiva del sujeto, en efecto, está en relación con el desencadenamiento de respuestas; cuando estas exigen una actividad «ponderativa» se complejiza así la función subjetual. Parecen existir, pues, unas condiciones evolutivas que tenderían a producir una ruptura de la signitividad en la conducta animal como exigencia de la eficacia en la supervivencia, por medio de una eficacia en la selección de señales y respuestas en animales hipercomplejos. En animales domésticos, como el perro, podemos observar en ocasiones este estado, digamos, de "perplejidad» producido por la hipercomplejidad psíquica. El animal se halla en contextos estimulares en que confluyen señales en conjunto desconcertantes. El animal parece entonces como inmóvil, perplejo, como si ponderara a su manera qué debe hacer; es decir, qué programa aplicar, si morder, si ladrar o si escaparse con el rabo entre piernas.

\subsection{Hipótesis básicas de la teoría de la hiperformalización}

Este sistema de hipótesis constituye propiamente el núcleo fuerte de la teoría. Es decir, lo que la teoría supone o hipotetiza que pudo suceder evolutivamente hasta producirse la emergencia del conocimiento racional humano. Podemos resumirlo en tres paquetes de hipótesis lógicamente derivados e interconectados.

1) Hiperformalización, hiperobjetivación, aprehensión de realidad. En el mundo animal se ha producido una cierta formalización que ha dado lugar a un cierto grado consecuente de objetivación en la conducta. Se podría, pues, hipotetizar que el hombre fuera un animal evolutivamente especializado en un nuevo, alto y específico grado de formalización. Podemos llamarlo hiperformalización. Y esta formalización específica y más intensa propia del psiquismo humano, hiperformalización, hubiera podido producir un modo más intenso, específicamente humano, en la aprehensión perceptivo-objetiva de los estímulos: podemos llamarlo hiperobjetivación. Por tanto, en estado de hiperobjetivación los objetos se percibirían con mayor nitidez e intensidad, destacarían con más fuerza por sí mismos y atraerían más atención psíquica del sujeto. Aparecerían con más fuerza como algo independiente, autónomo, unitario, permanente, estable, consistente, suficiente, "suyo» (término clásico utilizado por Zubiri)... A este modo específicamente humano en la percepción de los objetos (a esta riqueza nueva en la percepción objetiva) podríamos llamarlo «aprehensión 
sensible de realidad». Así, el hombre no percibiría ya puros estímulos o señales signitivas (que desencadenan instintivamente las respuestas automáticas en el mundo animal) sino que percibiría, o «aprehendería», «realidades». Todo sería un proceso «sentiente», una nueva manera de formalizar sensaciones. El psiquismo humano comenzaría a tener un estado nuevo, "contemplativo» de cosas, objetos, estímulos que están ahí por sí mismos con su propio y específico contenido. Dejaría de percibir «estímulos» para comenzar a percibir «realidades». El término «realidad» designaría la forma específicamente humana de percibir los objetos desde el estado neurológico de hiperformalización. En el hombre se habría acabado de producir la «ruptura de la signitividad» (del automatismo) imperante en el psiquismo animal (pero esta ruptura tendría sus precedentes en los estados protohumanos del psiquismo animal que antes hemos ido ponderando). El hombre comenzaría a preguntarse ya por el mundo en sí mismo, como real, a contemplarlo curiosamente como "realidad» que está ahí y a interesarse por él, por su forma de estar hecho, de estar ahí, y no sólo ya como pura «señal» para desencadenar automatismos instintivos. Parece evidente que sería imposible esta hipótesis de la «aprehensión de realidad» si la especie humana (los homínidos anteriores) no hubieran desarrollado poco a poco en sus mentes los procesos de representación asociativa, de clasificación y categorización, de abstracción y de imaginación. El término «realidad» designa una categorización abstracta de lo que tiene en común todo aquello que se presenta ahí, "sentientemente», ante el sujeto psíquico percibiente con un «de suyo», o sea, una entidad autónoma e independiente. El término «realidad» designa, por tanto, el resultado de un proceso de representación superior, anticipado en la abstracción animal, que ha dado origen a nuevas funciones psíquicas que permiten la emergencia consecuente de la razón.

2) Intelección de lo real como «estructura». Ahora bien, ¿cómo se presenta lo real constituido como «realidad» (es decir, como independiente, estable, consistente...) ante el psiquismo hiperformalizado humano? Esta teoría establece también la hipótesis de que el psiquismo humano en estado de hiperformalización, que contempla ya la «realidad» como tal, estaría en condiciones psíquicas apropiadas para advertir (darse cuenta, concienciar, o sea, construyendo una nueva representación superior abstracta) que la realidad es «real» como estructura. Una estructura, como sabemos por matemáticas, es un conjunto de elementos conectado entre sí por relaciones (operadores, proyectores) que producen una unidad resultante. Lo visualizamos en la estructura de vigas de hierro de una construcción, vg. un puente, conectadas relacionalmente de forma unitaria y consistente. El concepto de estructura es esencial en la ciencia. Ahora bien, generalizando, todo lo real se presenta como «siendo real» de forma «estructural». Así, la experiencia de la realidad de nuestro cuerpo, por ejemplo, es una experiencia estructural: un conjunto de elementos conectados en la unidad resultante. Por consiguiente, lo que la teoría de la hiperformalización supone es que las condiciones de hiperformalización habrían propiciado que el psiquismo humano, poco a poco, tras aprehender ya las cosas como «realidad», llegara a entender o advirtiera, cayera en la 
cuenta (se representara) de que «lo real es real como estructura» (Zubiri diría, de acuerdo con su concepto de inteligencia sentiente, que llegara a «inteligir sentientemente» que lo real es una estructura). Es evidente, por lo anterior, que estaríamos también hablando aquí de la hipótesis de que el psiquismo humano se representaría abstractamente que las cosas reales lo son de una forma tal que nosotros calificamos como «estructura».

3) Hipercomplejidad psíquica, razón y discurso estructural sobre la realidad. En esta teoría, al mismo tiempo que lo anterior, puede también hipotetizarse que el psiquismo humano (el homínido) pertenecería a aquellos animales que habrían evolucionado a un estado de hipercomplejidad psíquica. En esta situación, el psiquismo humano hipercomplejo habría inducido la emergencia de una nueva función del sistema conciencia-sujeto: la ponderación reflexiva de los estímulos como realidades para determinar la naturaleza de las respuestas a un medio progresivamente complejo. Ahora bien, al haber evolucionado también el psiquismo humano hacia una representación de la realidad como «estructura», esta nueva actividad psíquica ponderativa sería ya un análisis de la realidad como estructura. Para esta nueva actividad la especie humana se habría visto forzada por evolución progresiva a elevar el nivel de complejidad de las funciones de representación asociativa, clasificación, categorización, abstracción, imaginación y representación superior, ya presentes en el psiquismo animal. Así, la evolución de la mente animal en los homínidos preparó las condiciones que hicieron posible la emergencia de la razón humana. Es decir, cuando la nueva actividad ponderativa de la conciencia-sujeto se centra en torno a la «realidad como estructura» para seleccionar (o construir por imaginación) las respuestas adaptativas más eficaces adaptadas a la realidad de las cosas, nos hallamos ya entonces ante el nacimiento evolutivo, ante el orto de la razón. La razón se entendería así, dentro de esta serie de conjeturas, como el proceso de actividad psíquica desde el análisis de los datos perceptivos hasta construir representaciones de la realidad como estructura. Es entonces cuando este análisis y representación de estructuras permite a la razón ir desde lo que se ve (fenoménico) a lo que no se ve (transfenoménico). Pero lo transfenoménico es siempre aquel conjunto de contenidos que junto a lo fenoménico permiten entender la consistencia o suficiencia estructural de las cosas reales. La estructura que hace a las cosas reales consistentes está constituida por elementos reales, digamos, «visibles» $\mathrm{y}$ «no visibles». Este discurso que penetra hacia el fondo de las cosas, hacia su verdad última, es lo propio de la razón humana. En ello se ha desbordado el mundo del comportamiento animal entrando en una nueva dimensión emergente que permite al hombre un modo de ser real distinto, cualitativamente irreductible a los anteriores. El psiquismo humano no es una forma de psiquismo animal: es un cambio cualitativo que - aunque emergido en continuidad con el mundo animal - ha hecho entrar en un nuevo modo de ser real que ya no es animal. Es otra cosa, es "humano». En la ciencia es precisamente donde la especie humana ha llevado a su máximo rigor el proceso de este análisis estructural del mundo de los hechos para tratar de llegar a la verdad última de la realidad del universo. 
Por ello, cuando el proceso de percepción llega evolutivamente a la madurez y presenta un mundo suficientemente formalizado, es cuando la concienciasujeto puede advertir su «realidad» y su «estructura». El mundo de objetos animal se transforma en las «esencias objetivas», singulares, cuya constitución es una estructura (un sistema cíclico y clausurado de notas físicas). Se genera así la actividad psíquica (conocimiento) que tiende a producir una nueva representación en la mente de las estructuras de la realidad. La percepción es así un proceso de presentación de estructuras y el conocimiento es la continuación de este proceso hasta lograr una representación final de todo lo que constituye últimamente esas estructuras reales, pasando de lo fenoménico-perceptivo a la esencia ontológica de las cosas. La percepción presenta la estructura en superficie, fenoménicamente; el conocimiento, por la razón, trata de representar la estructura verdadera en profundidad de las cosas. El conocimiento prosigue por la razón la obra iniciada mecánicamente por la percepción; a saber, la obra de hacernos sentir un mundo (aunque sea fenoménicamente) construido por estructuras reales para alcanzar en él una supervivencia óptima.

\subsection{Conclusión: la proyección histórica de Suárez}

Suárez, en el siglo XVII, tuvo una potente intuición que tenía en germen lo que, de hecho, se produjo: la renovación de la filosofía escolástica por una nueva escuela que perduró en los siglos siguientes: la Segunda Escolástica. Al proyectar la teoría de Suárez sobre la prevalencia del singular sobre los siglos siguientes, podemos valorar hasta qué punto la evolución del pensamiento moderno siguió por vías similares a las de Suárez. El hecho es que, aunque al margen de Suárez, y por descontado de la filosofía escolástica, la manera de entender al hombre y su conocimiento, en la ciencia y en la filosofía moderna, ha ido en una línea que coincide (aunque formulado de otra forma) con las grandes intuiciones de Suárez. Las ideas de Suárez se reflejan de una forma muy especial sobre Xavier Zubiri. No cabe duda de que Zubiri se coloca en la tradición escolástica cristiana (aunque no era escolástico); la conoce y su filosofía original pudo quizá inspirarse en el enfoque suareciano. Si hacemos una proyección de Suárez sobre Zubiri no cabe duda de que aparecen nuevas informaciones provenientes de la ciencia moderna, que Suárez no podía ni atisbar. Sin embargo, la teoría de la hiperformalización de Zubiri avala, desde sus fundamentos etológicos, biológico-evolutivos, neurológicos, y despliega de una forma nueva, las intuiciones "primitivas», escolásticas, de Suárez. En este sentido puede decirse que las ideas de Suárez no han muerto. La historia ha hecho que se enriquezcan extraordinariamente. Zubiri puede entenderse, como hemos explicado, como una actualización de Suárez. Ambos autores, además, marcan también la continuidad «realista» de un estilo en la filosofía española que se mantiene durante siglos.

Universidad Autónoma de Madrid

Cátedra CTR, Universidad Comillas, Madrid

JAVIER MONSERRAT

jmonserrat@comillas.edu

[Artículo aprobado para publicación en enero de 2018]

PENSAMIENTO, vol. 74 (2018), núm. 279

pp. 31-61 